\title{
Vascular Endothelial Growth Factor Levels Difference among Hepatocellular Cancer Patients Based on Barcelona Clinic Liver Cancer Staging
}

\author{
Darmadi Darmadi $^{1 *}$ (D), Riska Habriel Ruslie ${ }^{2}$ iD, Cennikon Pakpahan ${ }^{3}$ (D) \\ ${ }^{1}$ Department of Internal Medicine, Faculty of Medicine, Universitas Sumatera Utara, Medan, Indonesia; ${ }^{2}$ Department of Child \\ Health, Faculty of Medicine, Universitas Prima Indonesia, Medan, Indonesia; ${ }^{3}$ Department of Biomedical Sciences, Faculty of \\ Medicine, Universitas Airlangga, Surabaya, Indonesia
}

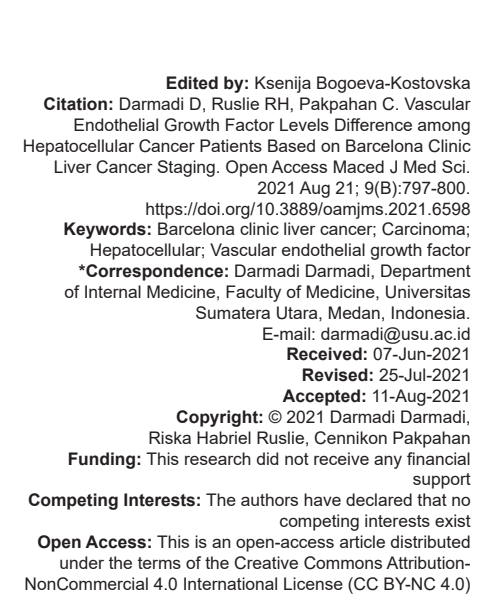

\section{Introduction}

Hepatocellular carcinoma (HCC) is one of the most common cancers worldwide [1], [2]. Approximately there were 400 million cases of HCC globally. In the USA, the incidence of HCC increases sharply in the past 2 decades [3]. In Haji Adam malik General Hospital Medan, Indonesia from 2009 to 2012, there were 153 patients with HCC. Patients were dominated by male gender and middle to advanced age. The reported mortality rate was $15 \%$ [4]. It carries high mortality rate, mainly due to lack of awareness for early screening. This is caused by asymptomatic feature of early-stage HCC. As the result, most patients come with advanced disease and poor survival rate [5], [6], [7]. In the other hand, despite specific treatment application, HCC's overall survival is not satisfactory because of relapse and metastasis after treatment [2], [8].

There are several methods in classifying the severity of HCC. Among them, barcelona clinic liver cancer (BCLC) staging remains to be preferred because it can predict the outcome and assist in deciding treatment option [9]. Recently, serum biomarker such as alphafetoprotein (AFP) is used to detect HCC at early stages in order to deliver prompt management [10]. Elevated AFP is suspected from differentiating hepatocyte in HCC [3]. However, serum AFP alone is not an adequate tool, particularly for small HCC [11], [12].

As we know that angiogenesis plays important role in cancer growth and metastasis [8], [13]. Increased metabolism and proliferation rate in cancer cells need higher demand of oxygen and other substrates which can be obtained from circulation. The larger the cancer size, the farther the distance between cells and supplying blood vessels. At this point, angiogenesis becomes extremely important for cancer's survival [2]. Numerous growth factors are involved in angiogenesis, one of them is the vascular endothelial growth factor (VEGF). VEGF contributes in cancer proliferation, survival, and migration by inducing mitogenesis and chemotaxis of endothelial cells and increasing vascular 
permeability [2], [7]. Liver tumors have abundant blood vessels, therefore, VEGF gives major impact toward their growth [2], [7], [12].

Earlier diagnosis will give better outcome in patients with HCC. Early diagnosis must be confirmed with rapid and accurate examination. Our study aimed to determine the difference of VEGF levels among HCC patients based on BCLC staging in hope to assist more accurate diagnosis and prudent management.

\section{Methods}

A cross-sectional study was conducted to determine the difference in VEGF levels among patients with HCC based on BCLC staging at Haji Adam Malik General Hospital Medan, Indonesia between January and December 2018. Patients aged 18 years or older with HCC were enrolled. Selection was made using consecutive sampling method. Patients with cholangiocarcinoma, hemangioma, and liver metastasis were excluded from the study. The diagnosis of HCC was confirmed by triphasic computed tomography-scanning (arterial hypervascularity followed by venous and/or delayed phase "washout") [15]. Circulating VEGF levels were determined from serum specimen using Quantikine Human VEGF-enzyme-linked immunosorbent assay (Quantikine R and D Systems Inc., Minneapolis). In addition, other baseline characteristics of patients such as sex, age, and the etiology of HCC were gathered. All patients were grouped based on BCLC staging. Data analysis was done with statistical software and the result will be presented in tables and figures. Kruskal Wallis-H test was used to determine the difference in VEGF levels based on BCLC staging. Statistical calculation was done at $95 \%$ confidence interval and $p<0.05$ was considered significant.

\section{Results}

A total of 60 patients were included in this study. Of all patients, 47 (78.3\%) were male. Mean age of patients was 61.4 (SD11.7) years. Hepatitis B was the most common etiology $(70.0 \%)$ of $\mathrm{HCC}$ in this study. Based on BCLC staging, 25 (41.7\%) patients were in Stage C, while $21(35.0 \%)$ patients were in Stage B. We found a median VEGF level in this study of $951.25 \mathrm{pg} / \mathrm{mL}$ with minimum and maximum value of $396.0 \mathrm{pg} / \mathrm{mL}$ and 2,561.4 pg/mL, respectively (Table 1).

Table 2 and Figure 1 showed differences in VEGF levels among patients with HCC based on BCLC staging. Statistical analysis using Kruskal Wallis $\mathrm{H}$-test was conducted. It can be observed that
Table 1: Baseline characteristics of patients

\begin{tabular}{ll}
\hline Characteristics & $\mathrm{n}=60$ \\
\hline Sex, $\mathrm{n}(\%)$ & \\
Male & $47(78.3)$ \\
Female & $13(21.7)$ \\
Mean age, years (SD) & $61.4(11.7)$ \\
Etiology, $\mathrm{n}(\%)$ & \\
Hepatitis B & $42(70.0)$ \\
Hepatitis C & $5(8.3)$ \\
Others & $13(21.7)$ \\
BCLC stages, $\mathrm{n}(\%)$ & \\
A & $5(8.3)$ \\
B & $21(35.0)$ \\
C & $25(41.7)$ \\
D & $9(15.0)$ \\
Median VEGF level, pg/mL (min-max) & $951.25(396.0-2,561.4)$ \\
\hline VEGF: Vascular endothelial growth factor, BCLC: Barcelona clinic liver cancer.
\end{tabular}

there was a statistically significant difference in VEGF levels $(p=0.006)$ where patients in stage $C$ and $D$ had higher VEGF levels compared to those in stage $A$ (1,009.6 pg/mL versus $578 \mathrm{pg} / \mathrm{mL}$ and 1,189.7 $\mathrm{pg} / \mathrm{mL}$ versus $578 \mathrm{pg} / \mathrm{mL}$, respectively). VEGF level in stage B patients $(875 \mathrm{pg} / \mathrm{mL})$ was higher than Stage A patients but the difference was not significant.

Table 2: VEGF levels difference based on BCLC staging

\begin{tabular}{lll}
\hline BCLC Stages & Median VEGF levels $(\mathrm{pg} / \mathrm{mL})$ & $\mathrm{p}^{*}$ \\
\hline BCLC A & $578(396-843)$ & 0.006 \\
BCLC B & $875(467-1,921)$ & \\
BCLC C & $1,009.6(544.6-2,561.4)^{\#}$ & \\
BCLC D & $1,189.7(622.9-2,456.6)^{\#}$ &
\end{tabular}
BCLC: Barcelona clinic liver cancer.

\section{Discussion}

Liver cancer is the fifth most common cancer worldwide and the second leading cause of death from cancer [2], [8]. This cancer affects males more often compared to females with a ratio of 2-3-1 [3], [15], [16]. Most patients with HCC aged 60 years or older [12], [17]. Several risk factors for HCC are hepatitis viral infection, genetic mutations, oxidative stress, and alteration of microenvironment [2], [12], [18]. In this

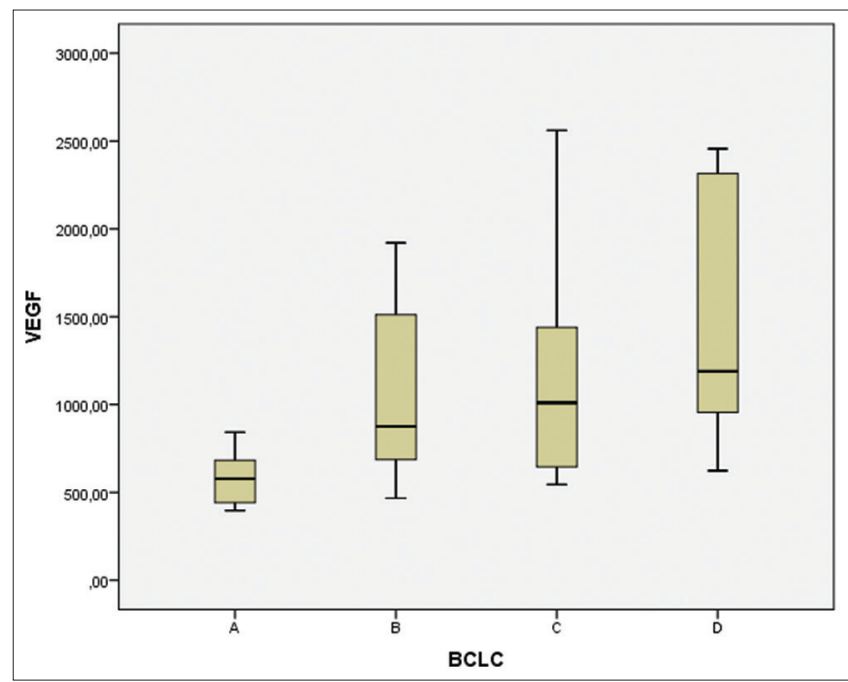

Figure 1: Boxplot diagram of vascular endothelial growth factor levels based on barcelona clinic liver cancer staging in patients with hepatocellular carcinoma 
study, $78.3 \%$ of patients was male with male-to-female ratio of 3.6-1. Mean age of patients in our study was 61.4 (SD11.7) years. Hepatitis viral infection was found in $47(78.3 \%)$ patients. Overall, baseline characteristics of patients in this study were similar to previous literatures.

Patients with HCC were classified according to BCLC staging into early-stage HCC (stage A), intermediate stage HCC (stage B), advanced stage (stage $\mathrm{C}$ ), and terminal stage (stage $\mathrm{D}$ ) based on tumor extension, liver functional reserve, physical status, and cancer-related symptoms [19], [20]. Patients in this study were classified according to BCLC staging. Most patients were in Stage C, followed by Stage B, Stage D, and Stage A. It can be inferred that most patients in this study were diagnosed in intermediate to the terminal stage of HCC. Delayed diagnosis could increase the risk of treatment failure and resulted in poor outcome.

Judah Folkman stated that all tumors are angiogenesis-dependent. Therefore, disrupting blood supply will kill the tumor [13]. VEGF is one of the growth factors for angiogenesis. VEGF specifically binds to VEGF receptor tyrosine kinase in endothelial cells to initiate the pathway of intracellular signal transduction that mediates angiogenesis and vascular permeability [21]. A study by Zhang et al. showed that knockdown of VEGF caused attenuation of migration, invasion, adhesion, and survival of HCC. These effects were mediated by increased expression of p53 as a tumor suppressor gene [13]. VEGF expression was increased in subjects with HCC compared to those with dysplastic nodule. VEGF had sensitivity and specificity of $68.7 \%$ and $31.2 \%$, respectively in diagnosing HCC [18]. Mukozu et al. reported that serum VEGF level was higher in patients with HCC compared to controls. Serum VEGF level was also higher in advanced HCC compared to liver cirrhosis and early HCC. There was no difference in serum VEGF level among HCC patients based on Child-Pugh classification. With a value of $108 \mathrm{pg} / \mathrm{mL}$ as the cut-off, serum VEGF had a sensitivity of $98 \%$ and specificity of $46 \%$ in detecting HCC [12]. This study also found that serum VEGF had a sensitivity of $78 \%$ and specificity of $84.7 \%$ in diagnosing HCC with a cut-off value of $225.14 \mathrm{pg} / \mathrm{mL}$ [7].

Li et al. found that elevated CD105 level was associated with higher VEGF level. This condition caused HCC to develop more aggressively and cause worse outcome [2]. Other biomarker was found to be associated with prognosis of HCC. The biomarker was angiogenic factor with G-patch and FHA domains 1 (AGGF1). AGGF1 was significantly higher in HCC tissue compared to surrounding normal tissue. In fact, AGGF1 was positively correlated with tissue VEGF expression [22]. A study by Yang et al. showed that endoplasmic reticulum resident oxidase $1 \alpha$ (ERO1 $\alpha)$ was associated with the development and outcome of HCC. Further, ERO1 $\alpha$ had positive correlation with VEGF-A, thus associated with angiogenesis [8]. Those studies confirmed our finding that VEGF plays the main role in HCC growth and metastasis. Past studies were in association with the result of our study. We found that VEGF level was associated with the development and metastasis of HCC. It was proved by statistical analysis results which showed a significant difference in VEGF level among patients with HCC based on BCLC staging $(p=0.006)$.

Without treatment, death will occur in 6-7 months after initial symptom of HCC. Survival can be prolonged up to 11-12 months with proper treatments. The outcome is also influenced by comorbidities and the nature of disease. Therefore, early detection of tumor is important in HCC management [3]. Treatment options for HCC are resection and transplantation, local tumor ablation, and chemoembolization [2], [13], [18]. Chemotherapy is one of the treatment options since liver transplantation is limited [3], [17]. After receiving chemotherapy, HCC levels decreased significantly regardless of the nature of disease. Again, they confirmed that VEGF level was useful in predicting tumor growth and invasion in HCC [17]. Another study reported that poorer outcome was associated with a higher level of serum VEGF [7]. Serum VEGF level was also useful in predicting outcome of patients with HCC after liver transplantation. Patient with higher serum VEGF level had a 12 times higher risk for having recurrence compared to those with low serum VEGF levels [23]. In this study, the higher level of VEGF will increase the stage of HCC. Patients with Stage D had the highest VEGF level, followed by patients in Stage C. The difference of VEGF levels between Stage D and $\mathrm{C}$ with Stage A patients was significant.

Our study had several limitations. We did not analyze comorbidities which might be present with HCC and influence the VEGF level. Finally, we did not analyze the accuracy of VEGF level in diagnosing HCC because of the absence of control group. Further study involving more patients and several centers is mandatory to confirm our result. As conclusion, there was a statistically significant difference in VEGF levels among HCC patients based on BCLC staging.

\section{References}

1. Tang A, Chernyak V, Kamaya A, Sirlin CB. Epidemiology of hepatocellular carcinoma: target population for surveillance and diagnosis. Abdom Radiol. 2018;43(1):13-25. https://doi. org/10.1007/s00261-017-1209-1

PMid:28647765

2. Li Y, Zhai Z, Liu D, Zhong X, Meng X, Yang Q, et al. CD105 promotes hepatocarcinoma cell invasion and metastasis through VEGF. Tumour Biol. 2015;36(2):737-45. https://doi. org/10.1007/s13277-014-2686-2

PMid:25286761

3. Siregar GA. Nonsurgical treatment for hepatocellular carcinoma. Univ Med. 2011;21:35-42. 
4. Butar-Butar AM. Profil Penderita Karsinoma Hepatoseluler di Rumah Sakit Umum Pusat Haji Adam Malik Medan pada tahun 2009-2012 [Thesis]. [Medan (North Sumatera)]: Universitas Sumatera Utara; 2013. https://doi.org/10.15851/jap.v4n2.819

5. He W, Xu M, Xu R, Zhou X, Ouyang J, Han H, et al. Inpatients knowledge about primary liver cancer and hepatitis. Asian Pac J Cancer Prev. 2013;14(8):4913-8. https://doi.org/10.7314/ apjcp.2013.14.8.4913

PMid:24083767

6. Pazgan-Simon M, Serafinska S, Janocha-Litwin J, Simon K Zuwala-Jagiello J. Diagnostic challenges in primary hepatocellular carcinoma: Case reports and review of the literature. Case Rep Oncol Med. 2015;2015:878763. https://doi. org/10.1155/2015/878763

PMid:25922775

7. Sharma BK, Srinivasan R, Kapil S, Singla B, Saini N, Chawla YK, et al. Serum levels of angiogenic and anti-angiogenic factors: their prognostic relevance in locally advanced hepatocellular carcinoma. Mol Cell Biochem. 2013;383(1-2):103-12. https:// doi.org/10.1007/s11010-013-1759-7

PMid:23912396

8. Yang S, Yang C, Yu F, Ding W, Hu Y, Cheng F, et al. Endoplasmic reticulum resident oxidase ERO1-Lalpha promotes hepatocellular carcinoma metastasis and angiogenesis through the S1PR1/STAT3/VEGF-A pathway. Cell Death Dis. 2018;9:1105. https://doi.org/10.1038/s41419-018-1134-4

9. Saraswat VA, Pandey G, Shetty S. Treatment algorithms for managing hepatocellular carcinoma. J Clin Exp Hepatol. 2014;4(Suppl 3):S80-9.

PMid:25755616

10. Chen H, Zhang Y, Li S, Li N, Chen Y, Zhang B, et al. Direct comparison of five serum biomarkers in early diagnosis of hepatocellular carcinoma. Cancer Manag Res. 2018;10:1947-58. https://doi.org/10.2147/cmar.s167036

PMid:30022853

11. Carr Bl, Akkiz H, Üsküdar O, Yalçın K, Guerra V, Kuran S, et al. HCC with low- and normal-serum alpha-fetoprotein levels. Clin Pract (Lond). 2018;15(1):453-64. PMid:29576865

12. Mukozu T, Nagai $H$, Matsui $D$, Kanekawa $T$, Sumino $Y$. Serum VEGF as a tumor marker in patients with HCVrelated liver cirrhosis and hepatocellular carcinoma. Anticancer Res. 2013;33(3):1013-21. https://doi.org/10.1016/ s0016-5085(12)63799-8 PMid:23482775

13. Zhang L, Wang J, Tang J, Kong X, Yang J, Zheng F, et al. VEGF is essential for the growth and migration of human hepatocellular carcinoma cells. Mol Biol Rep. 2012;39(5):5085-93. PMid:22161247

14. Pang G, Duan Z, Shao C, Zhao F, Zhong H, Shao G. Heterogeneity analysis of triphasic CT scan perfusion parameters in differential diagnosis of hepatocellular carcinoma and hemangioma. Medicine (Baltimore). 2018;97(38):e12512. https://doi.org/10.1097/md.0000000000012512

PMid:30235766

15. Liu P, Xie SH, Hu S, Cheng X, Gao T, Zhang C, et al. Age-specific sex difference in the incidence of hepatocellular carcinoma in the United States. Oncotarget. 2017;8(40):68131-7. https://doi. org/10.18632/oncotarget.19245 PMid:28978103

16. Wu EM, Wong LL, Hernandez BY, Ji JF, Jia W, Kwee SA, et al. Gender differences in hepatocellular cancer: Disparities in nonalcoholic fatty liver disease/steatohepatitis and liver transplantation. Hepatoma Res. 2018;4:66. https://doi. org/10.20517/2394-5079.2018.87 PMid:30687780

17. Matsui $D$, Nagai $H$, Mukozu T, Ogino $Y$, Sumino $Y$. VEGF in patients with advanced hepatocellular carcinoma receiving intraarterial chemotherapy. Anticancer Res. 2015;35(4):2205-10. PMid:25862879

18. Teixeira AC, Brasil IR, Torres AF, Tavora F. The evaluation of angiogenesis markers in hepatocellular carcinma and precursor lesions in liver explants from a single institution. Appl Immunohistochem Mol Morphol. 2018;26(5):330-6. https://doi. org/10.1097/pai.0000000000000426

PMid:27556821

19. Kinoshita A, Onoda H, Fushiya N, Koike K, Nishino H, Tajiri H. Staging systems for hepatocellular carcinoma: Current status and future perspectives. World J Hepatol. 2015;7(3):406-24. PMid:25848467

20. Darmadi D, Ruslie RH. Association between prothrombin induced by Vitamin K absence-II (PIVKA-II) and Barcelona clinic liver cancer (BCLC) stage, tumor size, portal venous thrombosis in hepatocellular carcinoma patients. Sains Malays. 2021;50:475-80. https://doi.org/10.17576/jsm-2021-5002-18

21. Watson CJ, Webb NJ, Bottomley MJ, Brenchley PE. Identification of polymorphisms within the vascular endothelial growth factor (VEGF) gene: Correlation with variation in VEGF protein production. Cytokine. 2000;12(8):1232-5. https://doi. org/10.1006/cyto.2000.0692

PMid:10930302

22. Wang W, Li G, Zhu J, Huang D, Zhou H, Zhong W, et al. Overexpression of AGGF1 is correlated with angiogenesis and poor prognosis of hepatocellular carcinoma. Med Oncol. 2015;32(4):131. https://doi.org/10.1007/s12032-015-0574-2 PMid:25796501

23. Campillo A, Solanas E, Morandeira MJ, Castiella T, Lorente S, Garcia-Gil FA, et al. Angiogenesis and proliferation markers in adjacent cirrhotic tissue could predict hepatocellular carcinoma outcome after liver transplantation. Eur J Gastroenterol Hepatol. 2014;26(8):871-9. https://doi.org/10.1097/meg.0000000000000131 PMid:24922356 